Michelle Henning

The Worlding of Light and Air: Dufaycolor and Selochrome in the 1930s

ORCiD

https://orcid.org/0000-0003-3798-7227

This work was supported by the Arts and Humanities Research Council under Grant AH/R014639/1.

Accepted for publication in Visual Culture in Britain on 27 August 2019.

Please note this is a pre-print version - the published version will be available at https://www.tandfonline.com/toc/rvcb20/current 


\section{The Worlding of Light and Air: Dufaycolor and Selochrome in the 1930s}

During the 1930s, new photographic technologies and practices addressed the difficulties of dealing with different kinds of climate, in Britain and her colonies. This article draws on archival material associated with two brands of photographic film manufactured in England by Ilford Limited: Selochrome and Dufaycolor. It describes these films as involved in a process of 'worlding', and as part of a 'photography complex' which produces the tropics and the British seaside as testing grounds for photography. Worlding involves the harnessing of light and air, the recalibration of bodies, the redistribution of sensory experiencs and the production of new materialities.

Keywords: photography industry, worlding, colour film, Dufaycolor, Ilford, tropics, actinism, body culture. 
Photography is an art and technology of light. It mobilizes and organizes first sunlight and then artificial light. It is dependent on atmosphere and climate: air dries photographic emulsions, atmospheric pollutants contaminate them; the darkness, the rain and the fog obstruct the act of taking a photograph; the temperature of chemicals affects the time they take to act, and so on. Procedures and techniques for the measure, control and classification of light, air and temperature are a central business of the photography industry. Much photography theory focuses on its temporal character, photography as a medium for the capture or fixing of time and motion. ${ }^{1}$ Here, I am interested in photography as something centrally engaged with harnessing the apparently natural and intangible qualities of light and air, and how this shapes modes of experiencing and comprehending different geographic places.

My research is centred on the 1920s and 1930s in Britain and the British Empire and rooted in the interwar archives of Ilford Limited and its subsidiaries. For the purposes of this article, I focus on two cultural and geographic sites: the British seaside and the tropics, and two brands of film: Selochrome, a panchromatic roll film, that is, a black and white film sensitive to a wide spectrum of light; and Dufaycolor, an additive colour transparency film available to amateur photographers in Britain from 1935. Both films were produced in Britain during the 1930s by subsidiaries of Ilford Limited. This company was the closest competitor of Kodak Limited, the British subsidiary of the American firm Eastman Kodak, which dominated the British amateur market. Selo was initially the product of a consortium of British photographic manufacturers, produced by the (nominally) separate Selo company, but by 1930 Ilford controlled it. ${ }^{2}$ By 1933 Selo brand film was the second most popular film in Britain, after Kodak, and Selochrome was possibly the fastest film on the market, according to Kodak's own assessment. ${ }^{3}$ Dufaycolor was the colour transparency film widely used in Britain from the mid 1930s, available before Agfacolor and Kodachrome and in a wider 
variety of formats. It was an additive colour reversal (transparency) film produced by Ilford Limited from 1935 and marketed by Dufay-Chromex from $1937 .^{4}$

By the 1930s, the British photographic community, which included numerous photographers across the Empire, shared quite specific notions, sometimes rooted in experience, of the optimum atmospheric and light conditions for the production of photographs. The community and industry also had a well-formulated set of norms regarding photographic technique and composition and the best subjects for photography, as well as largely unarticulated or implicit notions regarding gendered, racial, class-based and national characteristics and hierarchies. These norms and notions are subtly adjusted and revised via the new technologies of panchromatic and colour transparency film. They encouraged not just certain kinds of images but certain ways of moving, observing and photographing - ways of being a photographer.

To take an early example: in 1912, Edward Tickner Edwardes, a writer in Ilford Limited's free newsletter, Photographic Scraps, advised on making portraits of children at the English seaside. Since the beach at that time was a largely segregated place, children were to be found with women in that 'stretch of wet shore' filled with bathing machines and nursery maids, or changing tents. Male photographers cannot 'venture decorously' to these spaces, and instead 'confine themselves mostly to fishermen, their boats, and their netmending'. Edwardes therefore advises the 'lady' photographer, suggesting technique, recommending camera settings, and advising on a specific mode of deportment -'furtive, and swift, and often without the slightest premeditation'. ${ }^{5}$

This article, like many others, begins with actual photographic practice (Edwardes had seen work by women exhibitors in the photography shows) and then attempts to guide this practice, describing and interpreting existing scenes and behaviours and suggesting ones that may or may not yet exist - such as 'furtive' women photographers, wandering among the 
bathing-machines and tents, photographing the children of strangers. What slips from Tickner Edwardes grasp is the possibility of a different practice of photography among women, perhaps conducted in play and collaboration with children and in the context of already existing relationships. Overwriting such practices is Tickner Edwardes' now-familiar vision of a 'candid' photography which operates always from the outside, treating the subject of photography as the prey of a careful hunter.

\section{Worlding}

This study argues that norms and ways of understanding photography are evident not only in photographic discourse and practice but become 'built in' to photographic technology. In some respects, this is not a new observation: it was a central part of the post1968 critique of the cinematic apparatus in film studies, which recognized that ideology was not just something superimposed onto technologies after the fact, but structured and shaped the technical apparatus itself. Where I divert from that approach is that, instead of emphasizing how these inbuilt norms naturalize dominant ideas, I am interested in how they produce new materialities - how they facilitate certain atmospheres and affects, certain kinds of orientation and disposition, particular sensibilities, new temporalities and rhythms. The agent in this is not only the photographer or the film technology but what James L. Hevia calls the 'photography complex'. This encompasses a whole network of 'actants', both human and nonhuman, such as the camera, its optics and its chemicals, light, the technologies for print reproduction, the photographer, their subject, and the industrial production, communication and distribution networks that link all of these things. ${ }^{6}$

The photography complex is involved in what I am going to term a 'worlding' after Gayatri Chakravorty Spivak's use of the term. In two essays published in 1985, Spivak adopts the term 'worlding' in a deliberate 'vulgarization of Martin Heidegger's idea', 
referring in particular to Heidegger's essay 'The Origin of the Work of Art', and the distinction it establishes between 'world' and 'earth'. ${ }^{7}$ Heidegger makes 'world' into a verb partly to counter any idea that the world is made up of 'given things' that are 'just there', or that it is merely a representation superimposed on the 'tangible and perceptible realm in which we believe ourselves to be at home. ${ }^{8}$ Spivak suggests that in the context of colonial relations what is taken for 'earth' (stuff in general, entities that are not yet gathered together, brought into use and into sense) is actually already worlded. Heidegger's 'rift' (Riss) between earth and world is adopted as a means to identify the violence by which colonizers treat colonized space as 'uninscribed earth'. ${ }^{9}$ Spivak acknowledges this is a false analogy. She hijacks Heidegger's concept of 'worlding' to describe a process of overwriting an already existing world. The false analogy is productive, for it makes it possible to speak of the ongoing processes of violent reinscription that are characteristic of colonial and imperial relations and to read these in the archive. ${ }^{10}$

The term 'worlding' is now widely adopted across a number of disciplines, at times in ways that unhook it from both Heidegger and Spivak. ${ }^{11}$ Here I use the term, in relation to photography, for its uneasy and complex articulation of several things. First, for how it can be used to think of the photography complex as something that gathers together, rather than a set of representations overlaid on, the tangible and perceptible. ${ }^{12}$ Second, for how worlding (in Spivak rather than Heidegger) might describe a violence or violation. Third, for how it suggests simultaneously an ongoing process (a 'happening' in Heidegger) and a sealed-off entirety - we think of worlds as wholes, self-sufficient ecosystems, spheres, contained domains, not as something incomplete. Following Spivak, I see worlding in colonial terms, both in its reduction of a pre-existing world to earth, and in its production of hierarchies, of a particular order of things. This order of things is not static, nor does it exist purely as 
representation, but is experienced as an ongoing coming-into-being of new sensations, new atmospheres, new and distinct forms of social life.

In keeping with Spivak's approach I wish to avoid treating the archive as 'a quarry for facts', but instead to find the traces of this worlding enacted by the photography complex. ${ }^{13}$ My focus here is on the British seaside and the tropics because in this period, the seaside becomes a key site for summer holiday photography, while the tropics, especially those located within the British Empire, provided crucial export markets for the photography industry in general, and Ilford in particular. Strong competition at home and abroad from Kodak and Agfa led to Ilford emphasizing its Britishness and relying on imperial markets. Furthermore, both tropics and seaside are sites in which national identity seems to be experienced bodily and atmospherically: the seaside through racialized ideas and practices associated with health and fitness, and the tropics through the linking of race and climate. As I will show, the tropical climate is repeatedly described as a problem for photographic practice, and, at the time, this difficulty is aligned with the difficulties British bodies had in acclimatising themselves to these regions.

The tropics and the seaside are more than descriptive names. The tropics, as a category and as a set of defined sites, emerges in the context of European trade with the 'New World', through slavery, industry and trade, imperial and military practices. The British seaside emerges in the context of changes in work and leisure, and new health practices. Both are overseen by various forms of governance and regulation. The photography complex is involved in this worlding, indeed becomes increasingly central to it, not just because photographs were a fundamental means by which these places were depicted, but because these places became testing grounds for photography. New products and a new chemistry directly addressed their perceived characteristics and their idiosyncratic light and air. 
Problems were identified, expertise developed and institutionalized, new practices shaped and regulated, new technologies invented and marketed.

Edward Said has written how literature and letters are agents involved in 'bodying forth a world', shaping a reality. ${ }^{14}$ The photography complex also bodies forth a world, one which suppresses and overwrites other possible worlds. It produces places (such as the seaside and the tropics) with particular climates and atmospheres, and addresses newly adjusted sensoria, senses and bodies busy adapting themselves, as best they can, to new kinds of environment. The amateur photographer or 'photographic worker', in the terminology of the photographic press, has to find ways of inhabiting a place and a time, of moving through it, and of being with and handling equipment, of being in and out of the sun.

\section{Climate and culture}

'The tropics' is a European colonial term. Writing about tropical medicine, David Arnold has discussed how certain places came to be labelled as tropics. The definitions were more meteorological than geographical, and the emphasis on climate inseparable from moral and cultural judgments regarding the 'backwardness' of the hot, wet regions. The tropics were defined 'something culturally alien to, as well as environmentally distinct from, Europe and other parts of the temperate world'. ${ }^{15}$ Additionally, the term seems to carry with it the suggestion that these places are culturally 'intemperate', that is, lacking in moderation, control, regulation. Indeed, 'intemperate' was used to describe the climate of equatorial regions as early as the sixteenth century, suggesting, as Arnold says, something 'wild, unruly and dangerous', a 'malevolent' climate which nurtured violently extreme diseases. ${ }^{16}$ In the eighteenth and nineteenth centuries, international and military expansion brought Europeans into contact with unfamiliar diseases, but also made the tropics by transporting people, plants and diseases from one place to another. The category of the tropics and associated notions of 
the tropical migrated from the Americas to the British in Bengal, so that by the midnineteenth century there was a spreading perception of India as tropical, which went against older Orientalist views of the subcontinent, redescribing it in terms of its lush vegetation and dangerous diseases, and ignoring the fact that much of India is not geographically located in the tropics. ${ }^{17}$

By the end of the century, the photography complex was directly involved in the production of places as 'tropical', as Krista A. Thompson demonstrates in her research on the role of colonial government and British and American corporations in generating and circulating images of the Caribbean as tropical. ${ }^{18}$ Furthermore, just as the tropics were produced as a problem for bodies - particularly European bodies - they were also found to be problematic sites for photography, invariably contrasted with England, whose climate was treated as a norm and where photography seemed by contrast 'a simple matter'. ${ }^{19}$ Commentators in the British Journal of Photography (BJP), The Times and the photographic companies' own publications (such as the short-lived Ilford-Selo Record which was distributed throughout the Empire) repeatedly discussed the difficulties involved in tropical photography: from handling red-hot cameras; to using overheated developers that made the picture appear 'in a flash' and caused the gelatine emulsion to swell and soften; to the fixing baths in which emulsions detached themselves from glass plates and were found 'hiding in the corner of the dish, not unlike a sticky ju-jube' ${ }^{20}$ Exposed and undeveloped films would be mottled by storage in the heat, a 'distinct yellow haze' might appear, and moisture could attack cameras. ${ }^{21}$ Correspondents exchanged experiences and advice from different locations all described as tropical: from North Queensland (develop in the cooler morning time and use Ilford Plates that can stand up to 80 degrees Fahrenheit) to West Africa (bring your own darkroom and send films back to England for development, plus use an umbrella to protect your camera in the midday sun) to Brazil (avoid alkaline developers) and Bengal (use 
Selochrome - the editors of the Ilford-Selo Record used this claim by a correspondent to assure its readers that 'Selochrome can be relied on even under unfavourable atmospheric conditions'). ${ }^{22}$

Dufaycolor proved especially difficult: in 1937 one correspondent to the BJP described his difficulties with the film in the 'semi-tropical' conditions in Cape Town, South Africa. ${ }^{23}$ His letter shows how complicated and laborious the process was, and how he found the gelatine emulsion 'extremely soft', and 'frequently had the mortification of seeing the sensitive film disappear down the sink after second development, leaving the "reseau" intact on the celluloid base'. ${ }^{24}$ The high temperatures of the tropics were a particular problem with Dufaycolor, since it was a reversal process requiring two stages of development, and formulae to resolve this were publicized by the Dufay-Chromex Processing House in India. ${ }^{25}$ Tropical climates are repeatedly classified as 'trying', and, as with the discussions of tropical disease, the difficulties attributed to temperature and humidity become mixed with difficulties associated with infrastructure, 'backwardness' and the rich abundance of insect and plant life. A 1922 article by R. Dykes in the BJP, on photography in West Africa, contains some of the most vivid descriptions of preparing or developing plates in a "native hut' with no table, so that the author had to squat on the floor, plagued by scorpions, tarantula, giant flying beetles 'over half a pound in weight', and lizards that dropped from the ceiling. If that was not bad enough, insects would feed off gelatine emulsions during the drying process. ${ }^{26}$ The tropics, then, are both represented and experienced as an exceptional and excessive environment for photographers, and therefore as a problem to be solved.

It was a rare commentator who would actually point to something being easier in the tropics than in England. One such was J.S. Jenkins from the Eastern Extension Telegraph Co., Cocos-Keeling Island, who wrote that, in the Bromoil process, 'preparation and inking 
up of a print in the tropics is as easy as, if not actually easier than, in a temperate climate'. ${ }^{27}$ Another, H.F. Farmer, opened a 1923 article in the BJP with the assertion:

\begin{abstract}
'Although photography in the tropics is always understood to present innumerable difficulties, in actual practice the difficulties are far less than are met with in more temperate climates. In England, the photographer has not only to allow for constant changes of light, the difference between the light values in summer and in winter being enormous, but he has also to allow, in development, for a temperature which varies in any normal year from 80 degrees in summer to 20 in winter - a variation of 60 degrees. ${ }^{28}$
\end{abstract}

As Farmer suggests, the climate of the British Isles did not favour amateur photography.

Extreme and unpredictable temperature changes, and the likelihood of rain and fog, characterized an already short 'photography season', lasting from April to September, by which time there was already so little light that photographs could only be taken on ordinary cameras in the middle of the day. Selochrome black and white film, with its panchromatic emulsion, helped address this problem as it was rapid by the standards of the day (though only around 100 ISO by current measures). Amateur photographers were encouraged to use the available light meters, which were crude and inaccurate, to avoid persistent problems of underexposure.

The belief that England, in particular, provided the normal, or even ideal, environment for photographic practice is evident in publicity material for Dufaycolor. A booklet printed by Dufay-Chromex notes that 'leading experts in the film world have expressed the considered opinion that the English climate with its soft light is ideal for the taking of colour pictures. This combination of soft light and the latitude in Dufaycolor film place the colour photographer in this country in a most favourable position. ${ }^{, 29}$ Yet Dufaycolor's emphasis on holiday locations and especially seaside resorts as exceptional sites, inversely characterizes urban everyday life in Britain as dull, and as with the tropics, conflates culture with climate. For instance, a 1935 leaflet promoting Dufaycolor film 
asserted that the majority of holiday snapshots taken in Britain attempt to 'represent scenes of gaiety and happiness', far from 'the drabness of everyday existence', yet they fail because they lack colour. ${ }^{30}$ Black and white photography, this line of reasoning would suggest, brings both a literal and metaphorical greyness to even the sunniest scenes, while the summer holiday is the exception in an otherwise depressing culture.

By the 1930s there was a burgeoning market of photographic materials designed specifically for the humid, hot tropics, from Ilford's specialist darkroom chemicals to 'special tropical lacquer' to protect cameras. ${ }^{31}$ Photographers in Britain's imperial outposts were addressed by publications such as the Ilford-Selo Record, produced in numerous editions for different countries, from Burma to New Zealand, and 'Intended to be of assistance to all who practice photography'. The exchange of practical tips in such publications, alongside the promotion of specific products for tropical use (such as Ilford's Tropical Hardener), regulated and formulated tropical photographic practices. At the same time these reaffirmed the exceptional conditions of the tropics while helping to bring them more firmly under the grip of the photography complex.

\section{The regulation of light and air}

Photography would seem to be a medium ideally suited to a geographic region that 'receives the greatest intensity of direct sunlight on the planet'. ${ }^{32}$ However, archival sources suggest that the light of the tropics also seemed to present special difficulty to colonial photographers. The only place in Britain that seemed to have a similar quality of light was the seaside in summer: both tropics and seaside were characterized by their particularly 'actinic' sunlight. Actinic light is light that has the capacity to produce both photochemical and photobiological effects (such as tanning, sunburn, sunstroke). The term enters into common use in scientific and popular press discussions of photography from the 1850s onward. The distinction made 
sense in early photography, when emulsions recorded a very limited range of wavelengths, but became redundant as panchromatic films and plates became widely used, and almost all light visible to the human eye could be registered by the sensitive emulsion. In his 1942 book The Complete Photographer, Willard D. Morgan claimed, 'Since the advent of new supersensitive emulsions all light rays might be said to be actinic, for they all react on the film'. ${ }^{33}$ The term nevertheless continued to be used during the 1930s, for example, a 1937 article in The Amateur Photographer \& Cinematographer claimed that 'Light on the coast is very "actinic", 34

The term 'actinic' marks a peculiar and historically particular convergence between practices of photography and practices relating to the photosensitivity of human skin, especially white skin. Early accounts of actinic light as it relates to photography start to link it with geographic and national distinctions. For example, an 1850s article on 'Actinism' says that actinism varies across the globe, active on the whole American continent 'which explains the great beauty and perfection of American photographs', yet inactive in India where 'photographic pictures are obtained at all times with very great difficulty'. ${ }^{35}$ Although the term had limited use in science more widely, it cropped up, by the turn of the century, in discussions of light cures and therapies. In The Effects of Tropical Light on White Men (1905), Dr. Charles Edward Woodruff, a United States army surgeon who had been based in the Philippines, set out to address an existing theory that darker skin pigmentation evolved as a means to protect the body from 'actinic' rays, meaning here the shorter wavelengths, 'the violet, indigo, and blue and the ultra-violet rays' ${ }^{36}$ Using a version of Darwin's evolutionary theory to address the 'fitness' of peoples to their environment, he argued that the different human 'types' had evolved to be adapted to their specific environment, so that 'each type is unfitted for residence in any other zone markedly different from the ancestral one' ${ }^{37}$ Migration would doom a people within a few short generations. His 
argument against colonialism was thus made not in the name of equality but of racial differentiation, and depended on a slippage between scientific claims about the effect of light on cell degeneration to claims of racial and cultural degeneration. ${ }^{38}$

More commonly, actinism was used to legitimate notions of racial regeneration. By the 1920s and with the popularization of eugenics, actinic light is increasingly viewed as a means to strengthen 'the race', understood in nationalistic and cultural as well as biological terms. In his 1928 book, The Story of Artificial Silk, retired journalist and reformer Herbert N. Casson, for example, contrasted the ill-health of the British with the robust physiques of Chinese peasants and Africans (in general), whose 'semi-naked' state exposed them to the sun: 'They have the Ultra-Violet rays on the skin of the whole body ... The fact is that the bleached clothes-wrapped races are physically weaker than the natural-colour races. ${ }^{39}$ As Joanna Bourke comments, such racial comparisons were intended to galvanize British men: a revival of British masculinity being equated with a revival of imperial power. ${ }^{40}$ During the 1920s and '30s, tanned skin, previously associated with manual labour, was increasingly valued and linked to good health. Sunlight, swimming and beach life became tied to the eugenic ambition to shore up 'the race' (often meaning, rather parochially, the English) against degeneration. In this period, as Simon Carter argues, actinic cures grew in popularity along with the growing prominence of eugenic ideas about race, class and breeding, and the declining association of extreme paleness with beauty.

As Carter's research shows, sunshine cures or 'heliotherapy' overlapped with 'actinotherapy'. Since the turn of the century there had been increasing recognition of the link between various illnesses and the photosensitivity of skin. The public heath drive and the fashion for sunbathing was encouraged by organisations such as the Women's League of Health and Beauty and the Sunlight League. ${ }^{41}$ A whole socio-technical apparatus centring on sunshine, from sunlamps to sanatoria to lidos, alongside keep-fit and physical education 
literature, and the national fitness campaign (1937-1939), linked the health benefits of sunshine to a new concept of the body of the nation. ${ }^{42}$

In the various Ilford archives, numerous ads and promotional images evoke the effect of summer sunshine on pale skin. Dufaycolor cine film promised to 'bring the pink and rose flush of perfect health faithfully to your screen' while its roll film recorded 'faces tanned by the open air' ${ }^{43}$ Selo show cards and sample prints repeatedly depicted young, healthy looking white women and (to a lesser extent ) men, diving, dancing on the beach, leapfrogging, leaping to catch a ball, or holding a cloth or towel in the air to catch the sea breeze (Figure 1). The popular press used fine weather or the holiday season as an excuse to present swimsuitclad women for its male readers. The body culture of the 1930s fed a new propagandistic imagery. In Germany and the USSR, idealized sporting physiques of invariably white and youthful men and women concealed the violent suppression of a more diverse set of bodies. ${ }^{44}$ In Britain, as is evident in Selo publicity, beach bodies are implicitly set against two other kinds: the naturally brown-skinned, and the sickly white and rickety, vitamin D-starved Londoner who could not take a beach holiday. [figure 1 near here]

The sunlight campaigns were partly a reaction against modern urban life, and linked to smoke abatement and slum clearance campaigns. They pitted themselves against the fog, specifically the polluted fogs of London. These toxic fogs, largely the combined result of a misty basin city and coal pollution, had almost disappeared from central London by about 1910, returning only occasionally in the interwar years. As Bill Luckin has argued, they fuelled the discourse of eugenics, since the fog was thought to cause stunted growth and ill health among the working classes, and urban degeneration and moral decline, while sunshine and pure air were extolled as the route to the physical health needed to underpin the moral health of the nation and to halt the decline of Empire. ${ }^{45}$ 
Photography's sensitivity to contamination aligned it with the moral effects of sunlight and cleanliness - even while the photography industry was reliant on the coal tar industry and itself a major pollutant. While the atmosphere in the British Isles generally was recognized to be more blue than elsewhere, the the acrid yellow fogs of London drove early twentieth century news photographers toward new films and photographic plates that were sensitive to the yellow end of the spectrum. ${ }^{46}$ The industry located itself on the outskirts of London so it could access clean air and water, while being close to its major markets and suppliers, but by 1900 , the filthy city had expanded to meet it. ${ }^{47}$ Smoke abatement campaigns, partly funded by the gas industry, had promoted gas as a clean alternative to coal. As Peter Thorsheim writes, gas consumption moved the pollution from the city centre to the outskirts, and in suburbs such as Ilford (home of Ilford Limited) the gasworks 'contaminated the environment with smoke, sulphur, cyanide, heavy metals, and carcinogenic organic compounds'. ${ }^{48}$ The 'stunted' working classes were now to be found in the vicinity of the gasworks, while the acrid black smoke drove the well-off away. The Ilford archives demonstrate that the term 'fogging' in photography is directly connected to this polluted environment. In 1899, 25,000 glass plates were ruined through fogging at Ilford's factory, not long after the Ilford Gas Company had expanded their works. Ilford Limited began planning a new factory further away from London to avoid the pollution. In the meantime, engineers at the original plant invented a system to purify the air inside the factory, pioneering an early form of air-conditioning. ${ }^{49}$

In photography and in therapy, light and air demanded regulation. Since the late nineteenth century, as Chris Otter has argued, light was increasingly quantified, standardized and commodified. ${ }^{50}$ The use of photometry (the measurement of light) was crucial to the various Victorian technologies for artificial lighting, yet its yardstick was always the light perception of a human eye, something that frustrated and disheartened the 'illuminating 
engineers' he cites. ${ }^{51}$ In other words, techniques of light measurement crucial to artificial lighting and to photography were thoroughly dependent on the human body. Skin sensitivity was also conceived with reference to photography: Woodruff compared the sensitivity of skin to ultra-violet light with the sensitivity of photographic plates to other wavelengths, recommending a the use of 'a red light like the photographic dark-room' to counter the negative effects of actinic light on white men. ${ }^{52}$ Later, Dr. Caleb Saleeby, the chair of the Sunlight League, described skin as if it were a photographic plate or film, advocating men's dress reform to expose 'a larger surface of skin for the life-giving action of the ultra-violet rays of sunlight, the most precious medicinal and hygienic agents in the world' ${ }^{53}$

Precise and reliable light meters were not available to amateur photographers in Britain during the 1920 s and '30s ${ }^{54}$ Exposure tables were provided with films and published monthly in magazines such as The Home Photographer and Snapshots, to account for the different average lighting conditions in Britain at a given time of day in that particular month. Despite this rather haphazard approach, photographic exposure was becoming ever more closely managed, not only via the development of new meters, but via the refinement of camera equipment (especially lenses) and by the introduction of new emulsions, and new chemical developers. Photographs of the Ilford factories from the 1930s show women working in sensitometry - measuring and standardising the light sensitivity of photographic emulsions (Figure 2)- while both Ilford and Kodak Ltd.'s research reports of the period make regular use of sensitometric tests to demonstrate the differences between brands of film or to test out the claims made for new products. Colour transparency film, which had less exposure latitude than black and white negative film, was dependent on the refinement of both metering and sensitivity testing in the late1920s and early '30s. [figure 2 near here]

Attempts to more finely regulate exposure in photography find a correlate in the regulation of bodily exposure to light, and thereby of skin tanning, in actinotherapy. Carter 
discusses how arguments regarding the beneficial effects of sunlight were accompanied by warnings that actinic light could be hazardous, so that actinotherapy required 'caution, care and above all medical supervision' ${ }^{55}$ He sees this emphasis on careful scientific regulation and supervision of sun exposure, as a means to establish professional expertise. ${ }^{56}$ Saleeby set out defined (though admittedly largely disregarded) exposure times for sunbathing strictures relating to the best times of day to sunbathe, and the prescribed amount of time. ${ }^{57}$ This is reminiscent of, and probably no more precise than, the exposure time guidance for photography given in the magazines.

In photography, strictures and guidance about photographic practice not only justified and reinforced professional expertise, but explicitly addressed an 'amateur', a practitioner of photography or 'photographic worker' who must handle and respond to light and air. In tropical countries, the colonial 'photographic worker' was tasked with containing the excess - of damaging humidity, and heat, but also of actinic (burning) light. The labour that went into processing films in the tropics, especially colour films, helped to increase the distance between the tourist snapshooter and these gentlemen and lady 'workers' (actually often assisted by local labourers). ${ }^{58}$ At the British seaside it was a question of seizing opportunities for appropriate subjects and the right kind of film, the right time of day and year, following exposure guides provided by manufacturers, or the photographic press. The bright light and fresh air of the summer seaside contrasted with the city where darkness, smoke and fog restricted photography and threatened contamination of films and papers. Faster, more sensitive film extended the photography season and the photographing day, but produced a new problem at the coast: 'with the new ultra-fast films over-exposure is a very real danger' 59

\section{Colour as distributed sensation}


A number of writers have approached the question of how colour in photography becomes associated with skin colour and complicit in the establishing and reproduction of hierarchies of skin tone. This work emerged in the context of apparatus theory in film studies. As Brian Winston writes, normative whiteness results in 'film that more readily photographs Caucasians than other human types'. Drawing on Peter Wollen's point that colour film is not 'photography in natural colours' as 1930s marketing would have it, but that 'a whole technology of dyeing has intervened', Winston describes colour cinema film as 'a white technology' ${ }^{60}$ Film originated in a racially hierarchical and predominantly white culture, and had a continually disavowed 'cultural specificity'. ${ }^{61}$ 'Flesh tones' were taken to refer to white skin tones, and efforts to improve how film rendered them were always focussed on the attempt to match an already 'pleasing' Caucasian ideal. This orientation was built not only into the chemistry of the film but into the whole apparatus of cinema, including lighting, sets, costume and makeup. Thus the film apparatus worked to make 'ever more culturally determined products' which make it ever more difficult to produce 'good black skin tones' ${ }^{62}$

As I have suggested, my focus here is less in the reproduction of dominant ideology through film technology as in the ways in which the photography complex marshalls the material world. Apparatus theory, influenced by the work of Louis Althusser, sees technology as reproducing pre-existing ideologies, and ideology critique as requiring an understanding of the technical structure of reproduction. But the question of how film reproduces, or fails to reproduce, skin tones, is not just about how films reproduce ideological notions of beauty, but their role in producing a partition or 'distribution of the sensible' (partage du sensible), as Jacques Rancière defines it. Rancière rejects the concept of the apparatus in favour of the dispositif, treating technologies and instruments as means for the production of relations, for making partitions and arrangements, drawing the line between the perceptible and the imperceptible. ${ }^{63}$ The distribution of the sensible, Rancière explains, refers to 'the way in 
which ... a social destination is anticipated by the evidence of a perceptive universe, of a way of being, saying and seeing' ${ }^{64}$ It refers not just to a hierarchy of values, but to a distribution of sensory capacity, of the availability of sensual experiences, sensitivities, tastes and inclinations. It produces a 'common sense' that 'creates a certain sense of reality' by delimiting what is visible, how it is perceived and what meanings are attributed to it. ${ }^{65}$

The interwar photography complex delineated class distinctions as well as racial hierarchies, by drawing clear distinctions and division between types of amateur: the serious amateur, the snapshooter and the 'gift camera' owner. The first saw themselves as hobbyists with a respectable lineage, linked to the aristocratic pioneers of photography. The snapshooters were the largest class of consumers, constituting the major, lucrative market for roll film. They had limited grasp of photographic technique, bought simple cameras, and returned their films to the high-street chemist for development. They prized convenience and immediacy, so roll film manufacturers emphasized these: Dufaycolor's slogan 'Click - and it's colour!' (Figure 3), echoed Kodak's Brownie slogan 'You press the button: we do the rest'. The BJP did not conceal its disdain for these holiday amateurs, and mourned the decline of 'amateur photography as a flourishing national hobby' even while sales of roll film were peaking. ${ }^{66}$ The third category fared even worse in the eyes of both photographic press and industry: the amateur with the 'gift camera' (highly unlikely to use Dufaycolor because of the price of the film) was characterized as 'the unenterprising soul who acquired his camera through collecting cigarette coupons from his friends, and, having acquired it at the price of many sore throats among his smoker friends, uses it only for one or two beach snapshots on his annual holiday'. ${ }^{67}$ [figure 3 near here]

The holiday amateur was expected to find colour joyful and cheerful, and to link this to the notion of a happy holiday - this is the kind of 'sensual intensity' that Tom Gunning describes as being the aim of added colour in early cinema. ${ }^{68}$ When this kind of photographer 
is addressed, 'nature' is envisaged in such lurid colour and excess of cliché as to destroy any naturalism in the scene painted by the writer. A Dufaycolor cine film booklet exclaims '...$j u s t$ think of the fascination of seeing your screen glowing with colour, natural and sparkling'. ${ }^{69}$ Colour 'fascinates', seduces, hypnotizes. This hallucinatory, bewitching quality is affirmed in a mid- 1930s Dufaycolor booklet for users of 'miniature' (35mm film) cameras:

The worker who is most concerned with the photographing of holiday and domestic subjects will be able to impart to his pictures the glow and joyousness of cheerful glowing colour. In his photographs he will be able to see once again the verdant beauties of foliage, the blue of the sky, the deep green of the sea, the golden sway of waving corn, the red lips and rosy cheeks of his charming subject. ${ }^{70}$

The text implies that this vibrant and heightened perception already belongs to the snapshot photographer, who is merely recreating 'his' experience. It suggests a holiday-maker not just broadly aware of and affected by the colour of his environment, but deeply invested in it. This paragraph is immediately followed by advice for the 'serious amateur', concerned with using the film as a 'vehicle of artistic expression', and for this photographer, it suggests other kinds of subject matter: 'The pearly glow of water at eventide on a mist-swept loch, the fascination of old pewter, even the glorious richness of black velvet, can be rendered with loving accuracy'. ${ }^{71}$ Here, 'artistic expression' implies realism, but it is realism of a different sort: not just concerned with the accurate reproduction of colours but with the essential material qualities and the affective power of the photographed subject.

What line divides the golden corn and red lips desired by the holiday amateur from the mist swept loch and pewter of the serious amateur? In both cases a certain attention to colour and to materials, and a certain sensory immersion in the environment is imagined. For the holidaying amateur, colour offers a sensual, heightened reliving of memory. For the 'real' amateur photographer, it is promoted as a means of expression, able to communicate the full range of emotions. In the Dufaycolor promotion, the holiday amateur's colour palette is 
simple, almost primary (green, blue, gold and red), while the serious amateur is encouraged toward a palette that is almost monochrome (pearl, pewter and black). The distribution of sensory experience is inextricable, here, from the function of disposition and taste as a marker of distinction. As Scott Higgins has argued, an 'aesthetic of restraint' was increasingly dominating commercial colour cinema, subduing colour, reducing it to a servant of realism rather than a sensory feast. ${ }^{72}$ In 1930 s colour photography promotion too, the more serious and artistic amateur is also assumed to be more restrained, attracted to subtlety, nuance, and to differences of tone rather than differences of hue.

Historically, sensual intensity was associated by Europeans with the tropics, with their brilliant light and colour, with their supposedly 'primitive' native populations, and such abundant and excessive flora and fauna that, as Warwick Anderson summarizes, it 'verged on the grotesque'. ${ }^{73}$ Thompson argues that the category of the 'tropical garden' was a means by which the tourist industry reinvented Jamaica at the start of the twentieth century, largely through photography. ${ }^{74}$ Meanwhile, in the Bahamas, women of colour were "pictorially equated with nature', in a tradition that links exoticism and eroticism. Furthermore, in the mid-1930s, Thompson tells us, female market vendors were encouraged by the Nassau Development Board to decorate their stalls and themselves in bright colours (perhaps to address the growing use of colour film). ${ }^{75}$

The distribution of colour palettes along the lines of class, gender and race is complicated by the significance of nationalism and patriotism in the promotion of films. In Britain, Dufaycolor was largely promoted, not through scenes of exotic and 'colourful' locations (though travelogues were used to promote its cinema film), but pastoral images of Britain, of traditional villages, country houses and wooded landscapes. ${ }^{76}$ Brilliant colour was also linked to patriotic spectacle in Britain, with royal pageants one of the principal subjects for Dufaycolor cinema reels. ${ }^{77}$ In April 1935, The Ilford Courier advised Ilford's salespeople 
that the King's Silver Jubilee that Summer would provide plenty of opportunities for film and photography: 'Many people will wish to make pictures of the many happy events which will occur during the festivities — processions, firework displays, etc., all of which can be recorded photographically'. ${ }^{78}$ Simon Brown notes how early colour (motion) films centred on ideas of national identity: depicting the British countryside or London sights, and emphasising British traditions and heritage. Such films were part of a larger strategy 'designed to inspire patriotic feelings and so promote the appeal of home-grown films over foreign imports' ${ }^{79}$

The aesthetics of photography 'in natural colours' is also inseparable from wider changes in colour in the environment, including the arrival of brightly coloured 'artificial silk' (rayon) and neon lighting — both subjects that colour photographers are advised to seek out. ${ }^{80}$ Sarah Street and Joshua Yumibe describe a 'surge' of colour across the arts in the 1920s, emphasising that colour film built on earlier colour media (such as lantern slides and colour prints) and was accompanied by new colour practices that associated colour with 'modernity, mass democracy, and consumer culture' ${ }^{81}$ British photographers using Dufaycolor were encouraged to visit Kew Gardens (that 'centre of colonial transplantation' as Thompson puts it), where tropical nature might be viewed in tamed and orderly form. ${ }^{82}$ In 1937 Elizabeth Armstrong, writing in The Amateur Photographer and Cinematographer suggested that even at Kew, colour restraint should be exercised: 'The best results are obtained with fairly close-up subjects in good light, but preferably not in very contrasty sunlight. Sunlight slightly diffused by clouds or muslin is best — subdued colouring often gives a much more pleasing picture than a glaring mixture of blatant colour. ${ }^{93}$ Even while tropical regions and flora might be distinguished by their bright colours, to reproduce this would have been to abandon the refined subtlety that distinguished the 'civilized' or artistic palette. 


\section{World and earth}

If sensory apperception could be divided and attributed, so too could the activity and movements of the photographer. As noted with the example of Tickner Edwardes at the start of this article, the photography complex prescribed and produced certain ways of being and moving for photographers, in relation to specific sites (and sights). Both tropics and seaside were places that demanded specific ways of being a photographer and certain kinds of photograph. These sites produced the photographer, and the photography complex reciprocally produced them.

Worlding is not the superimposition of a representation on an earth that exists outside it. I want to make a clear distinction between the idea that photographic publicity and instruction materials and press articles promote a certain ideological view of photographic practice, and the argument that the photography complex is involved in worlding. Worlding, in the sense I give it here, is material and discursive. It works with light and air, colours and chemicals, with sensation and sense. It does not leave 'earth' unchanged, just as for Spivak, the 'worlding' conducted by colonialism, does not leave the colonized subjects and their worlds ready to be 'recovered, interpreted and curricularized' ${ }^{84}$ There is no unworlded photographic practice, no experience of light and air immune from divisions of class, race, gender and culture. At the same time, worlding is never a finished act but always an ongoing process which produces not just images and ways of making sense, but ways of being in the world, and forms of sensory experience.

7175 words 


\section{Acknowledgments}

The Ilford material used in this research is housed in archives at Redbridge Museum and Heritage Centre, Ilford; the Science and Industry Museum, Manchester; and the National Science and Media Museum in Bradford. Additional archives used were the Walgreen Boots Alliance Archives in Nottingham, and the Kodak Limited archive at the British Library, London. Thanks to all the archivists and collections officers for their help on this project, especially Dawn Galer, Emma Burgham, Kendra Bean, Judith Wright and Jayesh Tailor. Thanks to colleagues at the APP4 conference in St Petersburg, for pointing out the need to situate Ilford's promotional material in relation to body culture, and to Rowan Lear for her company and her insights on our shared trips to various archives. Sincere thanks too, to the editor and two anonymous reviewers whose recommendations were both timely and helpful. This work was supported by the Arts and Humanities Research Council.

\section{Bibliography}

'Actinism', The National Magazine 1 (1857): 181-183.

Anderson, Warwick. 'The Natures of Culture: Environment and Race in the Colonial Tropics'. In Nature in the global South: Environmental projects in South and Southeast Asia, ed. Paul R Greenough and Anna Lowenhaupt Tsing, 29-46. Durham:Duke University Press, 2003.

Arnold, David. 'The Place of "The Tropics" in Western Medical Ideas since 1750'. Tropical Medicine and International Health 2, no. 4 (1997): 303-313.

Armstrong, Elizabeth. 'Kew Gardens in Colour'. The Amateur Photographer and Cinematographer (June 16 1937), 627.

Bourke, Joanna. 'The Great Male Renunciation: Men’s Dress Reform in Inter-War Britain'. Journal of Design History 9, no. 1 (1996): 23-33. 
Brown, Simon. 'Colouring the Nation: Spectacle, Reality and British Natural Colour in the Silent and Early Sound Era'. Film History: An International Journal 21, no. 2 (2009): 139149.

Carter, Simon. Rise and Shine: Sunlight, Technology and Health. London: Berg Publishers, 2007.

Casson, Herbert N. The Story of Artificial Silk. London 1928.

Catford, A.J. 'Our first 75 years', Unpublished manuscript. 90/359/E1/6 Redbridge Museum and Heritage Centre.

'Dufaycolor Cine Film 9.5mm and 16mm' (undated) MS0232/5/31 Science and Industry Museum, Manchester.

'Dufaycolor: Everybody's Color Film: What it is and what it costs' (undated) MS0232/5/35 Science and Industry Museum, Manchester.

'Dufaycolor Processing in the Tropics'(1939) The British Journal of Photography 86, no. 4137 (1939) 519.

'Dufaycolor Roll Film and Film Pack' (1935) MS0232/5/21, Science and Industry Museum, Manchester.

Dykes, R. 'Photography in Tropical West Africa'.The British Journal of Photography 69, no. 3238 (May 26 1922): 310.

Edgerton, David E. H. 'Industrial Research in the British Photographic Industry, 1879-1939'. In The Challenge of New Technology: Innovation in British Business since 1850, edited by Liebenau, Jonathan, 106-134. Aldershot: Gower, 1988.

Farmer, H.F. 'Photography in the Tropics',. The British Journal of Photography 70, no. 3318 (1923): 748-750.

Frosh, Paul. The Poetics of Digital Media. Cambridge: Polity Press, 2018.

Goodsall, Robert H. On Holiday with a Camera: At the Seaside, In the Country, London: The Fountain Press, 1939.

Guillory, Sean. 'Physical Culture and Sport in Soviet Society: Propaganda, Acculturation, and Transformation in the 1920s and 1930s'. Revolutionary Russia 27, no. 1 (2014): 74-75. 
Gunkel, David J., and Paul A. Taylor. Heidegger and the Media. Cambridge: Polity Press, 2014.

Gunning, Tom. 1994. 'Colorful metaphors: the attraction of color in early silent cinema'. Fotogenia 1 (1994): 249-255.

Heidegger, Martin. 'The Origin of the Work of Art'. In Poetry, Language, Thought, trans. Albert Hofstadter. New York: Harper Perennial Classics, 2001.

Hercock, R. J. and Jones, G. A. Silver by the Ton. A history of Ilford Limited 1879-1979. Maidenhead: McGraw-Hill Book Company, 1979.

Hevia, James L. 2009. 'The Photography Complex: Exposing Boxer-Era China 1900-1901, Making Civilisation'. In Photographies East: The Camera and Its Histories in East and Southeast Asia, ed. R.C. Morris, 79-119. Durham,:Duke University, 2009.

Higgins, Scott, Harnessing the Technicolor Rainbow: Color Design in the 1930s. Austin: University of Texas Press, 2007.

Hiley, Nicholas. 'Hints to Newsfilm Cameramen' (1915). In The Researcher's Guide to British Newsreels III, ed. James Ballantyne. London: British Universities Film and Video Council, 1993.

Jackson, J. 'The Eclipse Of The Sun'. The Times (July 20 1932).

Jenkins, J. S. 'Bromoil in the Tropics'. The British Journal of Photography 75, (3564) (Aug 24 1928): 521.

Luckin, Bill. "'The heart and home of horror': The great London fogs of the late nineteenth century'. Social History 28, no. 1 (2003): 31-48.

Macdonald, Charlotte. 'Body and Self: learning to be modern in 1920s-1930s Britain'. Women's History Review 22, no. 2 (2013): 267-279.

Mikuriya, Junko Theresa. A History of Light: The Idea of Photography. London: Bloomsbury 2016.

Morgan, Willard D. The Complete Photographer. Vol. 1. Chicago IL: National Education Alliance, 1942. 
Otter, Chris. The Victorian Eye : A Political History of Light and Vision in Britain, 18001910. Chicago: University of Chicago Press, 2008.

Rancière, Jacques. The Politics of Aesthetics: The Distribution of the Sensible, trans. Gabriel Rockhill. London: Continuum, 2004.

Rancière, Jacques. The Emancipated Spectator, trans. Gregory Elliott. London: Verso, 2009.

Rau, Petra. 'The Fascist Body Beautiful and the Imperial Crisis in 1930s British Writing'. Journal of European Studies 39, no. 1 (2009): 5-35.

Said, Edward. The World, The Text and The Critic. Cambridge Mass.: Harvard UP, 1983.

Sanders, T.D., 'Sensitometric Tests on Selo and Kodak Roll-Films' (26 January 1932). A2827: H200, Kodak Limited Research Reports, Kodak Collection, British Library.

Saunders, J.E. 'Dufaycolor Photography for the Amateur Worker: Zoo Snapshots in Natural Colours' (undated) MS0232/5/34 Science and Industry Museum, Manchester.

Spivak, Gayatri Chakravorty. 'The Rani of Sirmur: An Essay in Reading the Archives'. History and Theory 24. no. 3 (Oct. 1985), pp. 247-272.

Spivak, Gayatri Chakravorty.'Three Women's Texts and a Critique of Imperialism', Critical Inquiry 12, no. 1 (Autumn, 1985): 243-261.

Steer, E.J. 'Letters to the Editor: Dufaycolor in Warm Climates'. The British Journal of Photography 84, no. 4050 (1937): 812.

Street, Sarah. 'Negotiating the Archives: The Natalie Kalmus Papers and the "Branding" of Technicolor in Britain and the United States'. The Moving Image: The Journal of the Association of Moving Image Archivists 11, no. 1 (2011): 1-24.

Street, Sarah and Joshua Yumibe. 'The Temporalities of Intermediality: Colour in cinema and the arts of the 1920s'. Early Popular Visual Culture 11, no. 2 (2013): 140-157.

'The Camera on the Coast'. The Amateur Photographer \& Cinematographer 58, (July 211937): 21.

The Dufaycolor Book, London: Dufay-Chromex Ltd. (undated) 
The Ilford-Selo Record 1935-36, MS0232/49/5, Museum of Science and Industry Manchester.

'The Rolleiflex in the Tropics'. The British Journal of Photography 82, no. 3938 (1935): 684.

'This Year of Jubilee'. The Ilford Courier 4, no. 2 (April 1935). Ref. 90/359/C3/B1 Ilford Limited Archive, Redbridge Museum and Heritage Centre.

Thompson, Krista A. An Eye for the Tropics: Tourism, Photography and Framing the Caribbean Picturesque. Durham: Duke University Press, 2006.

Thorsheim, Peter. 'The Paradox of Smokeless Fuels: Gas, Coke and the Environment in Britain, 1813-1949'. Environment and History 8, no. 4 (2002): 381-401.

Tickner Edwardes , Edward. 'Water Babies'. In Photographic Scraps 7, no. 276 (August 1912) Ilford Limited. MS0232/17/2, Science and Industry Museum, Manchester.

Walton, John K. The British Seaside: Holidays and Resorts in the Twentieth Century. Manchester: Manchester University Press, 2000.

Warburg, Agnes B. 'Roll-films, Film-Packs, and the User'. The British Journal of Photography 77, no. 3651 (1930): 239.

Winston, Brian. 'A Whole Technology of Dyeing: A Note on Ideology and the Apparatus of the Chromatic Moving Image'. Daedalus 114, no. 4 (Fall, 1985): 105-123.

Wollen, Peter. 'Cinema And Technology: A Historical Overview'. In The Cinematic Apparatus, ed. Teresa de Lauretis and Stephen Heath. New York: St. Martin's Press, 1980.

Woodruff, Charles Edward. The Effects of Tropical Light on White Men. New York: Rebman Company, 1905.

Zweiniger-Bargielowska, Ina. 'Building a British Superman: Physical Culture in Interwar Britain'.Journal of Contemporary History 41, no. 4 (2006): 595-610.

\section{Figure Captions}


Figure 1. Lithographs used to promote Selo film by Ilford Limited in 1939. Redbridge Library and Heritage Centre.

Figure 2. Women working in the Selo Sensitometric laboratory. This opened in 1938.

Photographer uncredited. Redbridge Library and Heritage Centre.

Figure 3. Dufaycolor leaflet. Redbridge Library and Heritage Centre. 
${ }^{1}$ A notable exception is Mikuriya, A History of Light.

${ }^{2}$ By the late 1930s, Kodak and Ilford had 90\% of the market. See Edgerton 'Industrial Research in the British Photographic Industry', and Hercock and Jones Silver by the Ton.

${ }^{3}$ Sanders, T.D., 'Sensitometric Tests on Selo and Kodak Roll-Films'.

${ }^{4}$ Dufaycolor cine film was marketed by the Spicer-Dufay company from 1932. By 1935, Ilford was in control of the process, and it introduced Dufaycolor transparency film for photographers. In 1937, Ilford gave the marketing and promotion of the film to a newly formed company -Dufay-Chromex - though Ilford remained the wholesaler. Availability of Dufaycolor can be gleaned from Boots the Chemist's Merchandise Bulletins available in the Walgreens Boots Alliance archive and from articles such as Armstrong, 'Kew Gardens in Colour'.

5 Tickner Edwardes, 'Water Babies'.

${ }^{6}$ Hevia, 'The Photography Complex'.

${ }^{7}$ Spivak, 'Three Women's Texts', 260.

${ }^{8}$ Heidegger, 'The Origin of the Work of Art', 43.

${ }^{9}$ Spivak, 'The Rani of Sirmur', 253.

${ }^{10}$ Ibid., 252-3. Spivak treats 'worlding' as both a textual and material process: she refers to 'dispatches, letters, consultations moving at the slow pace of horse, foot, ships laboriously rounding the Cape, and the quill pens of writers and copyists', and to Captain Geoffrey Birch's letter 'taking its time travelling five hundred odd miles across the Indo-Gangetic plains' while Birch himself is 'riding about in the Hills... engaged in consolidating the self of Europe by obliging the native to cathect the space of the Other on his home ground.'

Worlding happens in letters and on horseback.

${ }^{11}$ For useful discussions of media and Heidegger's concept of 'world disclosure' see Gunkel and Taylor, Heidegger and the Media, and Frosh, The Poetics of Digital Media.

${ }^{12}$ Heidegger, 'The Origin of the Work of Art', 44-47.

${ }^{13}$ Dominick LaCapra cited in Spivak 'The Rani of Sirmur', 250. 
${ }^{14}$ Said, The World, The Text and The Critic, 176.

${ }^{15}$ Arnold, 'The Place of 'The Tropics' in Western Medical Ideas', 303-6

${ }^{16}$ Ibid., 307.

${ }^{17}$ Ibid., 308-9.

${ }^{18}$ Thompson, An Eye for the Tropics, 5.

${ }^{19}$ Jackson, 'The Eclipse of the Sun', 11.

${ }^{20}$ Dykes, 'Photography in Tropical West Africa', 310. The term 'ju-jube' refers to a sticky, gum-like confectionary, named after its original ingredient the jujube fruit, which grow wild in parts of the tropics (notably in the Caribbean) and is cultivated widely across Asia. But, as one of the anonymous reviewers pointed out, 'ju-jube' also suggests 'ju-ju', a term that describes West African religious fetish practices.

${ }^{21}$ Ibid., 310.

${ }^{22}$ The Ilford-Selo Record 1935-36.

${ }^{23}$ Steer, 'Dufaycolor in Warm Climates', 812.

${ }^{24}$ Ibid. The 'reseau' refers to the fine grid of colour printed on the celluloid characteristic of the Dufay process.

25 'Dufaycolor Processing in the Tropics', 519.

${ }^{26}$ Dykes, 'Photography in Tropical West Africa', 310 (his emphasis).

${ }^{27}$ Jenkins, J. S. 'Bromoil in the Tropics', 521.

${ }^{28}$ Farmer, H.F. 'Photography in the Tropics', 748.

29 'Dufaycolor: Everybody’s Color Film'.

30 ‘Dufaycolor Roll Film and Film Pack' .

31 'The Rolleiflex in the Tropics'.

${ }^{32}$ Thompson, An Eye for the Tropics, 6. 
${ }^{33}$ Morgan, The Complete Photographer, 53.

${ }^{34}$ For example, a 1937 article claims that 'Light on the coast is very "actinic"'. 'The Camera on the Coast', 21.

35 ‘Actinism', The National Magazine, Vol. 1, 1857, 181-183, 183.

${ }^{36}$ Woodruff, The Effects of Tropical Light, 10

${ }^{37}$ Ibid. 3-4.

${ }^{38}$ Ibid. 236. Woodruff memorably claims that the decay of ancient Greek civilisation was due to the poor adaption of 'blond Greeks' to the Greek climate, citing as evidence of racial degeneration Socrates' 'lecherous countenance' and Diogenes 'defiance of all the decencies of life'.

${ }^{39}$ Casson, The Story of Artificial Silk, 92-3, cited in Bourke, 'The Great Male Renunciation', 26.

${ }^{40}$ Bourke, 'The Great Male Renunciation', 27.

${ }^{41}$ See Macdonald, 'Body and Self.'; Zweiniger-Bargielowska 'Building a British Superman'.

${ }^{42}$ Carter, Rise and Shine, 45; Macdonald 'Body and Self'.

43 'Dufaycolor Cine Film 9.5mm and 16mm', and 'Dufaycolor Roll Film and Film Pack'.

${ }^{44}$ Guillory, 'Physical Culture and Sport in Soviet Society'; Rau, 'The Fascist Body Beautiful'.

${ }^{45}$ Luckin, 'The heart and home of horror', 40; 44-45.

${ }^{46}$ Hiley, 'Hints to Newsfilm Cameramen'

${ }^{47}$ In 1789, when Alfred Harman established his factory in Ilford ,the population was 7,000 and the factory was surrounded by green fields on three sides. By 1900 the population had grown to 20,000. Hercock and Jones, Silver by the Ton, 47.

${ }^{48}$ Thorsheim, 'The Paradox of Smokeless Fuels', 394-5, 386.

${ }^{49}$ Catford 'Our first 75 years', 49-50. 
${ }^{50}$ Otter, The Victorian Eye, 136 and 162

${ }^{51}$ Ibid, 166-7.

${ }^{52}$ Woodruff, The Effects of Tropical Light, 17 and 109-110. He also cites a Dr. Gianni Busck who argued that certain substances in human blood (such as the anti-malarial quinine, taken by white people in the tropics) increased the sensitivity of the individual to actinic light and compared this to the dye sensitizers used in photographic emulsions to increase its sensitivity to different parts of the spectrum, though Woodruff is sceptical of this claim. Ibid, 124 .

${ }^{53}$ Saleeby cited in Bourke, 'The Great Male Renunciation', 26.

${ }^{54}$ This is clear from the 1920s and 30s editions of the Merchandise Bulletin of Boots the Chemist, as well as its in-house staff magazine The Bee. Both publications are held at the Walgreen Boots Alliance Archive.

${ }^{55}$ Carter Rise and Shine, 52

${ }^{56}$ Ibid., 61-2

${ }^{57}$ Walton, The British Seaside, 100.

${ }^{58}$ By the 1930s, tourist photography in the tropics was big business. In 1930 the influential colour photographer Agnes B. Warburg reported in the BJP on a cruise to the West Indies, where she observed the fellow-passengers using roll-film folding cameras, Leica style cameras and even shooting colour films. The ship's official photographers, she claims 'dealt with over 600 roll-films for D. and P. [developing and printing] during the cruise' - as well as making their own photographic record. Warburg herself attempted to develop her own films on board ship, before deciding to save them to develop in England. Warburg, 'Roll-Films, Film-Packs, and the User', 239.

59 'The Camera on the Coast', 21.

${ }^{60}$ Winston 'A Whole Technology of Dyeing', 105-8, drawing on Wollen, 'Cinema And Technology', 24.

${ }^{61}$ Winston 'A Whole Technology of Dyeing', 109.

${ }^{62}$ Ibid., 120-121. 
${ }^{63}$ Davide Panagia explains the distinction thus: 'The term dispositif imagines a technical instrument as a device for the production of relational arrangements and precisely not an apparatus for the reproduction of transcendental homologies' — as opposed to the Althusserian apparatus theory, which treats media as an 'influence machine', shaping values and ideology. Panagia, Rancière's Sentiments, 28.

${ }^{64}$ Rancière, The Politics of Aesthetics, 12.

${ }^{65}$ Rancière, The Emancipated Spectator, 102.

${ }^{66}$ The British Journal of Photography 1934.

${ }^{67}$ Saunders, 'Dufaycolor Photography for the Amateur Worker'.

${ }^{68}$ Gunning, 'Colorful metaphors', 249.

69 'Dufaycolor Cine Film 9.5mm and 16mm.'

70 'Dufaycolor for Miniature Cameras', 1. The description of colours and imagined scene is almost identical to a passage in Goodsall, On Holiday with a Camera,.46.

71 'Dufaycolor for Miniature Cameras', 1.

${ }^{72}$ Higgins, Harnessing the Technicolor Rainbow, 133.

${ }^{73}$ Anderson, 'The Natures of Culture', 36.

${ }^{74}$ Thompson, An Eye for the Tropics, 28-30, and 34. After the emancipation of the slaves the British perception of the island was of a squalid and ruined place. Thompson writes. 'Some of the roots and routes of still-enduring touristic images of Jamaica (and other parts of the Caribbean) as untouched natural landscapes, populated by coconut and banana trees and contented black " natives," all clothed in Edenic tropical luxuriance, can be traced to these New Jamaica campaigns'.

${ }^{75}$ Ibid, $107-110$ and 141.

${ }^{76}$ The Dufaycolor Book, published in several editions between 1935 and the 1950s, includes portraits of white women (and a horse), an advertising image for toothpaste, and on the back cover, a picture of a British country house.

${ }^{77}$ Brown, 'Colouring the Nation'141. 
78 'This Year of Jubilee', 3.

${ }^{79}$ Brown, 'Colouring the Nation', 142 and 146.

${ }^{80}$ Various editions of The Dufaycolor Book include a section on photographing neon lights. Artificial silk (rayon) clothing as a subject for photography is mentioned in Saunders, 'Dufaycolor Photography for the Amateur Worker'.

${ }^{81}$ Street and Yumibe, 'The Temporalities of Intermediality', 141 and 148. Elsewhere, Street writes about the extension of Natalie Kalmus's role as colour advisor for Technicolor film in Britain into a wider role as a public advocate for colour in dress and décor. Street, Negotiating the Archives 11-12.

${ }^{82}$ Thompson, An Eye for the Tropics, 55. In the National Science and Media Museum archive in Bradford examples of Dufaycolor photographs from the 1930s to 1950s depict beach scenes, and flowering gardens, including Kew Gardens. See the Dufaycolor research folders and PA Box 371

${ }^{83}$ Armstrong, 'Kew Gardens in Colour', 627.

${ }^{84}$ Spivak, 'The Rani of Sirmur', 247. 